\title{
Occurrence of pregnancy and pregnancy outcomes during isotretinoin therapy
}

\author{
David Henry MB ChB, Colin Dormuth ScD, Brandace Winquist PhD, Greg Carney BSc, \\ Shawn Bugden MSc PharmD, Gary Teare PhD, Linda E. Lévesque BSc(Pharm) PhD, Anick Bérard PhD, \\ J. Michael Paterson MSc, Robert W. Platt PhD; for the CNODES (Canadian Network for Observational \\ Drug Effect Studies) Investigators*
}

CMAJ Podcasts: author interview at: https://soundcloud.com/cmajpodcasts/151243-res

\begin{abstract}
Background: Isotretinoin, a teratogen, is widely used to treat cystic acne. Although the risks of pregnancy during isotretinoin therapy are well recognized, there are doubts about the level of adherence with the pregnancy prevention program in Canada. Our objective was to evaluate the effectiveness of the Canadian pregnancy prevention program in 4 provinces: British Columbia, Saskatchewan, Manitoba and Ontario.
\end{abstract}

Methods: Using administrative data, we identified 4 historical cohorts of female users of isotretinoin (aged 12-48 yr) for the period 1996 to 2011. We defined pregnancy using International Statistical Classification of Diseases and billing codes. One definition included only cases with documented pregnancy outcomes (highspecificity definition); the other definition also included individuals recorded as receiving prenatal care (high-sensitivity definition). We studied new courses of isotretinoin and detected pregnancies in 2 time windows: during isotretinoin treatment only and up to 42 weeks after treatment. Live births were followed for 1 year to identify congenital malformations.
Results: A total of 59271 female patients received 102308 courses of isotretinoin. Between $24.3 \%$ and $32.9 \%$ of participants received prescriptions for oral contraceptives while they were taking isotretinoin, compared with $28.3 \%$ to $35.9 \%$ in the 12 months before isotretinoin was started. According to the high-specificity definition of pregnancy, there were 186 pregnancies during isotretinoin treatment (3.1/1000 isotretinoin users), compared with 367 (6.2/1000 users) according to the high-sensitivity definition. By 42 weeks after treatment, there were 1473 pregnancies (24.9/1000 users), according to the highspecificity definition. Of these, 1331 (90.4\%) terminated spontaneously or were terminated by medical intervention. Among the 118 live births were $11(9.3 \%)$ cases of congenital malformation. Pregnancy rates during isotretinoin treatment remained constant between 1996 and 2011.

Interpretation: Adherence to the isotretinoin pregnancy prevention program in Canada was poor during the 15-year period of this study.
Competing interests:

Robert Platt received salary support during the course of the study from the Fonds de recherche du Québec -

Santé; he has also received personal or consulting fees for work unrelated to this project from Pfizer, Amgen, Abbvie and Novartis. No other competing interests were declared.

This article has been peer reviewed.

\section{*The CNODES}

Investigators are listed at the end of the article.

Accepted: Jan. 22, 2016 Online: Apr. 25, 2016

Correspondence to: David Henry, david.henry@ices.on.ca CMAJ 2016. DOI:10.1503 /cmaj.151243
I sotretinoin is used widely to treat severe and scarring cystic acne. The drug was first approved for use in Canada in 1983. It is a potent teratogen, ${ }^{1,2}$ and female users should avoid pregnancy during and for at least 1 month after the end of treatment. ${ }^{3}$ Isotretinoin exposure can lead to a range of severe craniofacial, cardiac and central nervous system abnormalities and may also lead to increased rates of spontaneous and elective abortion. ${ }^{1-3}$ The average age of isotretinoin users in Canada is estimated to be 24 years, and half of all prescriptions are written for female patients. ${ }^{4}$

Although the risks of pregnancy during isotretinoin therapy have been recognized for more than 30 years, repeated studies have shown poor adherence to pregnancy prevention guidelines in several countries, including Canada. ${ }^{3-8}$

Several factors may have increased the probability of inadvertent exposure. The first is the marketing of several generic products by companies that may not have the prescriber and consumer education resources of the original manufacturer. ${ }^{9}$ The second is a rapid increase in use of the drug and a shift to prescribing isotretinoin for milder forms of acne. ${ }^{10}$ The latter was reflected in a population-based study in Quebec, in which $64 \%$ of first-time isotretinoin recipients did not have a history of having used 
other anti-acne medications, a breach of prescribing guidelines. ${ }^{7}$ The risk of exposure may have been further increased by online availability of multiple isotretinoin products without prescription or proper risk information. ${ }^{11}$

The teratogenic effects of isotretinoin are preventable, and there have been numerous attempts to minimize the risk of pregnancy during treatment. Since teratogenicity was first documented in humans, the Dermatologic and Ophthalmic Drugs Advisory Committee of the US Food and Drug Administration (FDA) has made frequent recommendations to balance the needs of patients with severe acne with the imperative to prevent fetal exposure. ${ }^{12}$ Central to these efforts has been a worldwide, sponsordeveloped Pregnancy Prevention Program launched in 1988. ${ }^{12}$ Following the introduction of generic isotretinoin products in 2002, the FDA launched an integrated risk management program for all isotretinoin products in $2006 .{ }^{13}$ As part of this mandatory program (known as iPLEDGE; www.ipledgeprogram.com) patients must register, complete an informed consent form and receive counselling about the risks associated with the drug, and women of childbearing age must comply with required pregnancy testing. Only registered prescribers and pharmacists are permitted to prescribe and dispense isotretinoin.

Canada has not adopted a program equivalent to iPLEDGE. The program that is in place in Canada requires informed written consent, 2 pregnancy tests with negative results before starting isotretinoin and 2 reliable forms of contraception during treatment. ${ }^{3}$ Health Canada periodically reviews the pregnancy prevention program with manufacturers. Isotretinoin use and pregnancy have been studied in Quebec ${ }^{7}$ and through counselling services, ${ }^{5}$ but there has been no population-based study of isotretinoin use and pregnancy outcomes in a large and representative sample of isotretinoin users in Canada. As part of a review of its isotretinoin pregnancy prevention program, Health Canada asked the Canadian Network for Observational Drug Effect Studies (www.cnodes.ca), part of the Drug Safety and Effectiveness Network (www.cihr-irsc.gc.ca/e/40269.html), to report on the frequency of pregnancy during isotretinoin use in several Canadian provinces and the outcomes of these pregnancies.

The objectives of this study were to estimate the frequency of pregnancy during and immediately after treatment with isotretinoin, the number of potentially exposed pregnancies that go to term, the number of resulting fetal abnormalities and whether these rates have changed over time. We studied the use of oral contraceptives, both concomitant with isotretinoin therapy and in the year before treatment, and also estimated the proportions of female isotretinoin users who had tried alternative acne treatments before commencing their first course of isotretinoin.

\section{Methods}

This retrospective cohort study included all female patients aged 12-48 years, in 4 provinces, for whom one or more prescriptions for isotretinoin were dispensed between 1996 and 2011. We analyzed linked administrative health datasets from British Columbia, Saskatchewan, Manitoba and Ontario (combined population 20.7 million). In Ontario, coverage for isotretinoin was limited to those receiving social assistance. In BC, Saskatchewan and Manitoba, coverage was more comprehensive.

Pregnancies were identified using both hospital separation records and medical services insurance data, on the basis of diagnostic codes from the International Classification of Diseases, 9th revision (ICD-9) and the International Statistical Classification of Diseases and Related Health Problems, 10th revision, enhanced Canadian version (ICD-10-CA), as well as provincial medical services procedure codes (see Appendix 1, available at www.cmaj.ca/lookup/ suppl/doi:10.1503/cmaj.151243/-/DC1). We studied only pregnancies that occurred during isotretinoin treatment or that could be reasonably assumed to have had exposure.

All of the analyses were conducted with deidentified data. The study was reviewed and approved by research ethics bodies in each of the 4 provinces. Further details are provided in Appendix 2, available at www.cmaj.ca/lookup/ suppl/doi:10.1503/cmaj.151243/-/DC1.

\section{Cohort entry}

Female patients were included in the cohort when they began an episode of isotretinoin therapy during the study period. All residents covered by their respective provincial drug insurance programs for at least 12 months before the start of the study were eligible for inclusion. Patients who had multiple episodes of drug use were entered into the cohort more than once. A series of prescriptions was considered a continuous episode of drug therapy if a prescription was filled within the time period between the previous prescription fill date plus the number of days' supply dispensed in the previous prescription plus 30 days. If the time between prescription refills was longer, the patient was re-entered into the cohort at the time of the next episode of use. 


\section{Definition of exposure}

Fetal exposure to isotretinoin was defined as occurring when the date of a valid diagnostic or procedure code for pregnancy (see Appendix 1) fell within the dates covered by the isotretinoin prescriptions dispensed to an individual. This definition will have underestimated the true exposure rates because the first record of a diagnostic code (e.g., spontaneous abortion or birth) may have been after the cessation of isotretinoin treatment and therefore not counted under this definition.

A range of follow-up periods were considered, all of which increased the apparent rate of exposed pregnancies beyond the base case assumption; however, they all included potential exposure later in pregnancy when the fetus would not have been at maximum risk (where the period of maximum risk was defined as the first 4 weeks after conception). To address the problem of underestimation of overall exposure, and to study all pregnancy outcomes, we also documented any relevant diagnostic code with a date that fell within the period of isotretinoin treatment and, in the case of births, up to 42 weeks after the end of treatment. Spontaneous and induced abortions were included if they occurred within 26 weeks after treatment ended or within 22 weeks of the 1-month "washout period."

\section{Identification of pregnancies}

In an era of self-administered pregnancy tests, identification of pregnancy in administrative data is challenging. ${ }^{14,15}$ With the exception of births, gestational age could not be determined, given that the onset of pregnancy was not documented in the administrative health databases, and the majority of pregnancies were terminated. Two sets of diagnostic and procedural codes were used to estimate the occurrence of pregnancy during treatment (Appendix 1). The more conservative approach (high-specificity definition) included only those diagnostic codes for pregnancy outcomes (i.e., abnormal products of conception, spontaneous or medical abortions, live births or stillbirths).

Recognizing that many participants will have experienced early pregnancy losses not captured by administrative health databases, a second, broader definition was operationalized, which included diagnostic codes for care provided primarily in medical clinics (e.g., supervision of high-risk pregnancy). These diagnoses allowed us to identify not only early pregnancy losses, but also mothers who may have completed their pregnancy out of hospital or out of province.

Both hospital discharge abstracts and provincial health insurance (medical billing) data were used to identify the diagnostic codes of interest (Appendix 1). Relevant billing codes were added to better capture care provided in clinics. As an example, Appendix 1 lists relevant procedure codes from one provincial insurance plan (Saskatchewan). Equivalent codes were used for the other 3 provinces. Pregnancy outcomes were grouped as follows: live births, stillbirths, live births with congenital malformations, induced abortions (including pregnancy terminations due to fetal abnormalities) and spontaneous abortions. Births were subsequently validated using vital statistics birth registration files.

All pregnancy cases were reviewed manually by researchers at each site to ensure that none was counted more than once and that care codes linked to a later pregnancy outside the exposure period were removed. Hospital, medical services and birth registration data were used together to identify documented cases of congenital malformations in live or stillborn infants. In the case of pregnancy terminations following prenatal diagnosis, certain diagnostic codes enabled the identification of anomalies (ICD-9 codes 655.0, 655.1, 655.5, 655.9; ICD-10-CA codes O35.0, O35.1, O35.5, O35.9).

\section{Results}

\section{Characteristics of participants and treatment courses}

In total, there were 59271 female isotretinoin users in the relevant age group who received 102308 courses of isotretinoin in BC, Saskatchewan, Manitoba and Ontario between 1996 and 2011. Most were urban dwellers with mean ages (by province) ranging from 22.9 to 26.7 years. The median duration of therapy in one course varied from 68 days in Ontario to 113 days in Manitoba (see Table 1 for additional details on characteristics of participants and treatment courses). Social status data were not available for all 4 provinces. In Ontario, $89.5 \%$ of participants $(3897 / 4355)$ were recorded as welfare recipients, who tended to be older and took shorter courses of treatment than isotretinoin users in the other provinces.

\section{Concomitant and prior use of oral contraceptives and other acne drugs}

The use of oral contraceptives in the 12 months before entering the cohort ranged from $28.3 \%$ in Ontario to $35.9 \%$ in BC (Table 2). By comparison, use of oral contraceptives during isotretinoin therapy was not higher, ranging from $24.3 \%$ in Saskatchewan to $32.9 \%$ in Manitoba. Use of other acne drugs before isotretinoin treatment ranged from $45.4 \%$ in Ontario to $72.0 \%$ in BC. 


\section{Pregnancies recorded during and after the treatment period}

Depending on the definition (high-specificity v. high-sensitivity), overall pregnancy rates during isotretinoin treatment ranged from a low of 1.7 per 1000 female isotretinoin users (Saskatchewan, high-specificity definition) to a high of 18.6 per 1000 users (Ontario, high-sensitivity definition) (Table 3). Rates were generally higher in the Ontario cohort. In the other provinces, they were in the range of 2-3 per 1000 users (highspecificity definition) to 4-6 per 1000 users (high-sensitivity definition). Although we differentiated the code lists, the codes for the highsensitivity definition were actually quite specific for pregnancy and unlikely to lead to many false positives (Appendix 1). As such, the latter figure of 4-6 per 1000 users probably best represents the pregnancy rates for typical users of isotretinoin in Canada. It should be noted that this value is conservative, given that it includes only pregnancies that occurred during the period of active isotretinoin treatment.
When we pooled data from the 4 provinces using the codes for the high-sensitivity definition, there was no evidence of changes over time in rates of pregnancy during isotretinoin treatment: 5 per 1000 isotretinoin users between 1996 and 1999, 4 per 1000 users between 2000 and 2003, 5 per 1000 users between 2004 and 2007, and 4 per 1000 users between 2008 and 2011.

When the follow-up period was extended to the treatment period plus 42 weeks, the estimated pregnancy rates were, on average, 42.3 per 1000 isotretinoin users (high-sensitivity definition), ranging from 21.7 per 1000 users in Saskatchewan to 116.9 per 1000 users in Ontario. Because of the exposure time window, these are effectively annual rates of pregnancy.

\section{Pregnancy outcomes}

The widened exposure time window (treatment plus 42 weeks) enabled us to study pregnancy outcomes (Table 4). Over the 15 years of the study, 1473 pregnancies were recorded (using

Table 1: Characteristics of female isotretinoin users

\begin{tabular}{|c|c|c|c|c|}
\hline \multirow[b]{2}{*}{ Characteristic } & \multicolumn{4}{|c|}{ Province; no. (\%) of participants* } \\
\hline & British Columbia & Saskatchewan & Manitoba & Ontario \\
\hline No. of participants & 37285 & 10890 & 6741 & 4355 \\
\hline $\begin{array}{l}\text { No. of courses of } \\
\text { medication }\end{array}$ & 64541 & 20591 & 10314 & 6862 \\
\hline Age, yr, mean $\pm S D$ & $23.6 \pm 8.7$ & $22.9 \pm 9.0$ & $23.6 \pm 8.5$ & $26.7 \pm 9.2$ \\
\hline Urban residence & NA & $7653(70.3)$ & 4476 (66.4) & $4052(93.0)$ \\
\hline Welfare recipient & NA & NA & $216 \quad(3.2)$ & $3897(89.5)$ \\
\hline $\begin{array}{l}\text { Duration of single course of } \\
\text { therapy, } d \text {, median (IQR) }\end{array}$ & $94(30-144)$ & $85(30-144)$ & $113(60-152)$ & $68(30-133)$ \\
\hline Dose, mg, mean \pm SD & $41.9 \pm 25.3$ & $44.2 \pm 20.4$ & $44.7 \pm 20.2$ & $43.9 \pm 26.3$ \\
\hline
\end{tabular}

Table 2: Use of oral contraceptives and other acne medications before and during isotretinoin treatment

\begin{tabular}{|c|c|c|c|c|}
\hline \multirow[b]{2}{*}{ Other medication use } & \multicolumn{4}{|c|}{ Province; no. (\%) of participants } \\
\hline & $\begin{array}{c}\text { British Columbia } \\
n=37285\end{array}$ & $\begin{array}{c}\text { Saskatchewan } \\
n=10890\end{array}$ & $\begin{array}{l}\text { Manitoba } \\
n=6741\end{array}$ & $\begin{array}{l}\text { Ontario } \\
n=4355\end{array}$ \\
\hline \multicolumn{5}{|c|}{ During isotretinoin therapy } \\
\hline Oral contraceptives & $11378(30.5)$ & $2651(24.3)$ & 2219 (32.9) & $1183(27.2)$ \\
\hline Other acne medications & $11020(29.6)$ & $1332(12.2)$ & 1407 (20.9) & $891(20.5)$ \\
\hline \multicolumn{5}{|c|}{$\begin{array}{l}\text { In } 12 \text { mo before isotretinoin } \\
\text { therapy }\end{array}$} \\
\hline Oral contraceptives & 13398 (35.9) & $3153(29.0)$ & $2268(33.6)$ & $1233(28.3)$ \\
\hline Other acne medications & $26863(72.0)$ & $6606(60.7)$ & $4283(63.5)$ & $1976(45.4)$ \\
\hline
\end{tabular}


the high-specificity definition), of which 118 $(8.0 \%)$ resulted in live births, $1041(70.7 \%)$ were medically induced abortions and 290 (19.7\%) were spontaneous losses. The lowest rate of induced abortions was seen in Saskatchewan, and the highest live birth rates in Saskatchewan and Ontario. In BC, only $2.6 \%$ of exposed pregnancies resulted in live births. Of the 118 pregnancies that resulted in live births, $11(9.3 \%)$ were identified as having congenital malformations. We cannot break down this number by province because of suppression rules related to small cell size. We are similarly unable to report further details from each of the provinces on the nature of these congenital malformations.

\section{Interpretation}

This study of data from 4 Canadian provinces documented consistent occurrence of pregnancy during treatment with isotretinoin. Rates were highest in Ontario, among a cohort receiving social assistance. Higher rates of pregnancy among isotretinoin users from lower socioeconomic groups has previously been reported for Quebec. ${ }^{7}$ Using the rates documented in the other provinces as a more representative value, and including both high-specificity and highsensitivity definitions, we estimate that between 4 and 6 per 1000 female isotretinoin users conceive while taking a 3-month course of isotretinoin in Canada. A systematic review of data from pregnancy prevention programs in Europe documented pregnancy rates of between 0.2 and 1 per 1000 female isotretinoin users. ${ }^{8}$ However, differences in methods prevent a direct comparison of these rates. The European review found that the majority of exposed pregnancies were terminated, as was the situation in this study.

From the rates of pregnancy documented during isotretinoin use, we can estimate an annual pregnancy rate during treatment of 16 to 24 per

Table 3: Pregnancies during isotretinoin treatment and up to 42 weeks after the end of treatment, determined by high-sensitivity and high-specificity definitions of pregnancy

\begin{tabular}{|c|c|c|c|c|c|c|c|c|c|c|}
\hline \multirow[b]{3}{*}{ Province } & \multirow[b]{3}{*}{$\begin{array}{l}\text { No. of } \\
\text { patients }\end{array}$} & \multirow[b]{3}{*}{$\begin{array}{l}\text { No. of } \\
\text { courses }\end{array}$} & \multicolumn{4}{|c|}{ During isotretinoin treatment } & \multicolumn{4}{|c|}{ Up to 42 wk after treatment } \\
\hline & & & \multicolumn{2}{|c|}{$\begin{array}{l}\text { Pregnancies: } \\
\text { high-specificity }\end{array}$} & \multicolumn{2}{|c|}{$\begin{array}{l}\text { Pregnancies: } \\
\text { high-sensitivity }\end{array}$} & \multicolumn{2}{|c|}{$\begin{array}{c}\text { Pregnancies: } \\
\text { high-specificity }\end{array}$} & \multicolumn{2}{|c|}{$\begin{array}{l}\text { Pregnancies: } \\
\text { high-sensitivity }\end{array}$} \\
\hline & & & No. & $\begin{array}{l}\text { No. per } \\
1000 \text { users }\end{array}$ & No. & $\begin{array}{l}\text { No. per } \\
1000 \text { users }\end{array}$ & No. & $\begin{array}{l}\text { No. per } \\
1000 \text { users }\end{array}$ & No. & $\begin{array}{l}\text { No. per } \\
1000 \text { users }\end{array}$ \\
\hline British Columbia & 37285 & 64541 & 106 & 2.8 & 212 & 5.7 & 912 & 24.5 & 1581 & 42.4 \\
\hline Manitoba & 6741 & 10314 & 19 & 2.8 & 24 & 3.6 & 150 & 22.3 & 181 & 26.9 \\
\hline Ontario & 4355 & 6862 & 43 & 9.9 & 81 & 18.6 & 315 & 72.3 & 509 & 116.9 \\
\hline Total or rate & 59271 & 102308 & 186 & 3.1 & 367 & 6.2 & 1473 & 24.9 & 2507 & 42.3 \\
\hline
\end{tabular}

Table 4: Outcomes of pregnancies among isotretinoin users (during treatment or up to 42 weeks after the end of treatment), based on the high-specificity definition of pregnancy

\begin{tabular}{|c|c|c|c|c|c|}
\hline \multirow[b]{2}{*}{ Outcome } & \multicolumn{5}{|c|}{ Province; no. (\%) of pregnancies } \\
\hline & $\mathrm{BC}$ & Saskatchewan & Manitoba* & Ontariot & Overall \\
\hline All pregnancies & 912 & 96 & 150 & 315 & 1473 \\
\hline Spontaneous pregnancy lossesł & $199(21.8)$ & $34(35.4)$ & $34(22.7)$ & $23 \quad(7.3)$ & $290(19.7)$ \\
\hline Induced abortion (including TOPFA) & $689(75.5)$ & $44(45.8)$ & $103(68.7)$ & $205(65.1)$ & $1041 \quad(70.7)$ \\
\hline $\begin{array}{l}\text { Live birth, with or without congenital } \\
\text { malformation }\end{array}$ & $24 \quad(2.6)$ & $18(18.8)$ & $11 \quad(7.3)$ & $65(20.6)$ & $118 \quad(8.0)$ \\
\hline $\begin{array}{l}\text { Live birth with congenital } \\
\text { malformation }\end{array}$ & Suppressed§ & Suppressed§ & Suppressed§ & Suppressed§ & 119 \\
\hline \multicolumn{6}{|c|}{$\begin{array}{l}\text { Note: BC = British Columbia, TOPFA = termination of pregnancy for fetal abnormality. } \\
\text { *For } 2 \text { cases in Manitoba, the outcome could not be categorized because of small-cell suppression rules. } \\
\text { tFor } 22 \text { cases in Ontario, no pregnancy outcome was documented. } \\
\text { fIncludes spontaneous abortions and a very small number of stillbirths. } \\
\text { \$Data suppressed to protect patient confidentiality. } \\
\text { १The cases with outcome of congenital malformation }(n=11) \text { represented } 0.7 \% \text { of all pregnancies and } 9.3 \% \text { of live births. }\end{array}$} \\
\hline
\end{tabular}


1000 female users. From Statistics Canada data for the relevant age group, we estimate an annual unplanned pregnancy rate of about 50 per 1000 female patients. ${ }^{16}$ These estimates imply that contraceptive measures during isotretinoin treatment in Canada are achieving an effectiveness of about $50 \%$ to $70 \%$, short of the ideal when a potent teratogen is being ingested.

There was a large difference in the number of pregnancies identified between the narrow and wide time windows for exposure, whether identified by the high-specificity or the highsensitivity definition. Using the high-specificity definition, we estimated that the pregnancy rate in the cohort during the first 90 days was about 2 per day, compared with a rate of more than 4 per day in the subsequent 294-day (42-week) follow-up period, after treatment stopped. We assume that some individuals relaxed their contraceptive measures after ceasing isotretinoin and that this accounts for the higher rate in the latter phase of the follow-up period. Many in the latter group were probably not exposed during a theoretically vulnerable exposure period for the fetus and, as noted, we could not obtain gestational age. Most of the pregnancies were terminated anyway, which indicates that isotretinoin treatment had both major direct and major indirect effects on the course of these pregnancies.

Of 118 live births with fetal exposure to isotretinoin over the period 1996 to 2011, 11 $(9.3 \%)$ were recorded as having congenital malformations. A crude scaling of these estimates to the population of Canada suggests that 1 or 2 children are born with congenital anomalies each year after maternal use of isotretinoin. We do not know the severity of these abnormalities or whether the relation with isotretinoin is causal. Rates of major congenital abnormalities among live births in Canada are reportedly in the range of $3 \%$ to $5 \% .{ }^{17} \mathrm{We}$ are not comparing this rate with what we observed among isotretinoin users, given that our purpose was not to measure the association between isotretinoin use and fetal abnormality. This association is well known. ${ }^{1,2}$ It is likely that diagnostic ultrasound examinations were performed for some of the pregnancies documented here and that the findings led to a decision to terminate the pregnancy.

The rates of concomitant use of oral contraceptives that we documented were rather low. We may have underestimated this value because of individuals who received prescriptions for oral contraceptives privately, directly from their doctor or from family planning services, or who had an extensive supply from a prescription issued outside the time period covered by our records. However, these caveats also apply to the measurement of oral contraceptive use in the 12 months before isotretinoin treatment, and the 2 rates of use appeared similar. We also concede that we did not document the use of intrauterine devices and cannot determine the use of barrier methods. The Canadian recommendations require 2 negative pregnancy test results before and use of 2 reliable forms of contraception during and until at least 1 month after isotretinoin treatment. ${ }^{18}$ Clearly there is incomplete compliance with this standard, as reflected by the low use of oral contraceptives and the constant pregnancy rate over the period of this study.

Our findings are in line with the literature. Failure to use adequate contraception is, predictably, the leading reason for pregnancy during isotretinoin treatment. Internationally, between $7 \%$ and $60 \%$ of female users have been found not to use any form of contraception during treatment. ${ }^{19,20}$ As many as $80 \%$ do not use 2 methods of birth control, as recommended. ${ }^{21}$

Another area of poor adherence with prescribing advice is the use of less restricted and safer treatments for acne before graduating to isotretinoin. In this study, between $45.4 \%$ and $72.0 \%$ of isotretinoin users had received prescriptions for other acne treatments in the previous year, with the lowest rate in the Ontario cohort. This observation and the low use of oral contraceptives point to clear areas for improvement in the management of acne and isotretinoin therapy.

Several studies in the US, Canada and Europe have documented low use of effective contraception, low compliance with pregnancy prevention programs, birth defects from in utero exposure and high rates of termination of pregnancy after maternal isotretinoin use..$^{5-8,22-24}$ One study reported a risk of becoming pregnant while taking isotretinoin of 8 per 1000 person-years of treatment. ${ }^{22}$ This is lower than the annual rate calculated for Canada and is likely to be an underestimate because of under-reporting to voluntary registries. More relevant to our results is the study in Quebec, which covered the period from 1988 to 2002 and reported a rate of 10.5 per 1000 isotretinoin users, ${ }^{7}$ somewhat higher than our estimate of 4-6 per 1000 users, but closer to the rate seen in the Ontario cohort. In the Quebec study, the researchers used a broader selection of pregnancy codes, including perinatal and fetal complications, and also included patients who were pregnant when they started treatment. ${ }^{7}$ Eighty-four percent of pregnancies were terminated, similar to what we found for $\mathrm{BC}$ but higher than the 4-province average of $70.7 \%$ reported here. Among 90 exposed pregnancies in the Quebec cohort, there were 9 live births, one with major malformations. ${ }^{7}$ 


\section{Limitations}

There are important limitations to this work, some of which have already been discussed. For example, as noted earlier, we did not have access to the results of pregnancy tests and instead used a combination of diagnostic and insurance codes. Even our high-sensitivity definition of pregnancy was more restrictive than that used in the Quebec study, which may have led to us to underestimate the rate of exposed pregnancies. We used a conservative time window to identify pregnancies detected only during active treatment with isotretinoin. For this reason, we also performed analyses with a widened time window of 42 weeks after cessation of isotretinoin, with the additional aim of following potentially exposed pregnancies to term. Although this approach probably led us to include conceptions that occurred outside a vulnerable period of fetal exposure, it is notable that more than $70 \%$ of the pregnancies were terminated medically, and for $\mathrm{BC}$, this figure was even higher. This implies that both the patients and their health care professionals were concerned about the possibility of fetal exposure to isotretinoin or had ultrasound evidence of fetal abnormality.

Because we relied on administrative data, we cannot be sure that female patients for whom isotretinoin was dispensed actually took the drug. Finally, the most recent data are now quite dated (up to 2011 only), because of delays in access to data in one province. However, the rates of pregnancy were consistent over a 15 -year period, and we doubt that access to more recent data would change our main conclusions.

\section{Conclusion}

There was surprising consistency in pregnancy rates during isotretinoin treatment between 1996 and 2011, despite the Canadian pregnancy prevention program. US studies have shown that the impact of the iPLEDGE program also appears to have been modest in terms of increased uptake of oral contraceptives and reduced numbers of exposed pregnancies. ${ }^{23,24} \mathrm{It}$ is clear from this experience and from studies in Europe that modifying contraceptive behaviour in this setting is difficult. Nevertheless, medical practitioners and patients must be constantly reminded of the risks of isotretinoin to the fetus and must adhere to the policy that mandates effective contraceptive measures.

\section{References}

1. Lammer EJ, Chen DT, Hoar RM, et al. Retinoic acid embryopathy. N Engl J Med 1985;313:837-41.

2. Rosa FW. Teratogenicity of isotretinoin. Lancet 1983;2:513.

3. Choi JS, Koren G, Nulman I. Pregnancy and isotretinoin therapy. CMAJ 2013; 185:411-3.
4. Azoulay L, Oraichi D, Bérard A. Patterns and utilization of isotretinoin from 1984 to 2003: Is there need for concern? Eur $J$ Clin Pharmacol 2006;62:667-74.

5. Pastuszak A, Koren G, Rieder MJ. Use of the Retinoid Pregnancy Prevention Program in Canada: patterns of contraception use in women treated with isotretinoin and etretinate. Reprod Toxicol 1994;8:63-8.

6. Atanackovic G, Koren G. Fetal exposure to oral isotretinoin failure to comply with the Pregnancy Prevention Program. CMAJ 1999;160:1719-20.

7. Bérard A, Azoulay L, Koren G, et al. Isotretinoin, pregnancies, abortions, and birth defects: a population-based perspective. $\mathrm{Br}$ J Clin Pharmacol 2007;63:196-205

8. Crijns HJ, Strauss SM, Gispen-de Vied C, et al. Compliance with pregnancy prevention programmes of isotretinoin in Europe: a systematic review. Br J Dermatol 2011;164:238-44.

9. Honein MA, Moore CA, Erickson JD. Can we ensure the safe use of known human teratogens? Introduction of generic isotretinoin in the US as an example. Drug Saf 2004;27:1069-80.

10. Wysowski DK, Swann J, Vega A. Use of isotretinoin (Accutane) in the United States: rapid increase from 1992 through 2000. J Am Acad Dermatol 2002;46:505-9.

11. Lott JP, Kovarik CL. Availability of oral isotretinoin and terbinafine on the Internet. J Am Acad Dermatol 2010;62:153-4.

12. Dermatologic and Ophthalmic Drugs Advisory Committee. Briefing information: Accutane NF (isotretinoin) capsules NDA 21-177. Silver Spring (MD): US Food and Drug Administration; 2000. Available: www.fda.gov/ohrms/dockets/ac/00/ backgrd/3639b1.htm (accessed 2016 Jan. 11).

13. iPLEDGE: committed to pregnancy prevention [web-based risk management program]. iPLEDGE; 2005. Available: https:// www.ipledgeprogram.com/ (accessed 2016 Apr. 11).

14. Margulis AV, Setoguchi S, Mittleman MA, et al. Algorithms to estimate the beginning of pregnancy in administrative databases. Pharmacoepidemiol Drug Saf 2013;22:16-24.

15. Raebel MA, Ellis JL, Andrade SE. Evaluation of gestational age and admission date assumptions used to determine prenatal drug exposure from administrative data. Pharmacoepidemiol Drug Saf 2005;14:829-36.

16. Pregnancy outcomes by age group (total pregnancies). Ottawa: Statistics Canada; 2008. Available: www.statcan.gc.ca/tables-tableaux/ sum-som/101/cst01/hlth65a-eng.htm (accessed 2016 Apr. 13).

17. Congenital anomalies in Canada 2013. A perinatal health surveillance report. Ottawa: Public Health Agency of Canada; 2013. Available: http://publications.gc.ca/collections/collection_2014/ aspc-phac/HP35-40-2013-eng.pdf (accessed 2016 Jan. 26).

18. Consumer information. Accutane Roche Mississauga (ON): F. Hoffmann-La Roche; 2015. Available: www.rochecanada.com/ en/products/pharmaceuticals/consumer_information/accutane roche.html (accessed 2016 Apr. 15).

19. Garcia-Bournissen F, Tsur L, Goldstein LH, et al. Fetal exposure to isotretinoin — an international problem. Reprod Toxicol 2008; 25:124-8.

20. Boucher N, Beaulac-Baillargeon L. Pregnancy prevention among women taking isotretinoin: failure to comply with the recommendations. Can Fam Physician 2006;52:338-9.

21. Honein MA, Paulozzi LJ, Erickson JD. Continued occurrence of Accutane-exposed pregnancies. Teratology 2001;64:142-7.

22. Mitchell AA, Van Bennekom CM, Louik C. A pregnancyprevention program in women of childbearing age receiving isotretinoin. N Engl J Med 1995;333:101-6.

23. Shin J, Cheetham TC, Wong L, et al. The impact of the iPLEDGE program of isotretinoin fetal exposure in an integrated health care system. J Am Acad Dermatol 2011;65:1117-25.

24. Pinheiro SP, Kang EM, Kim CY, et al. Concomitant use of isotretinoin and contraceptives before and after iPledge in the United States. Pharmacoepidemiol Drug Saf 2013;22:1251-7.

Affiliations: Institute for Clinical Evaluative Sciences (Henry, Lévesque, Paterson), Toronto, Ont.; Institute of Health Policy, Management and Evaluation (Henry), University of Toronto, Toronto, Ont.; Faculty of Medicine (Dormuth, Carney), University of British Columbia, Vancouver, BC; Saskatchewan Health Quality Council (Winquist, Teare), Saskatoon, Sask.; College of Pharmacy (Bugden), Faculty of Health Sciences, University of Manitoba, Winnipeg, Man.; Centre for Health Services and Policy Research (Lévesque), Queen's University, Kingston, Ont.; Faculté de pharmacie (Bérard), Université de Montréal, Montréal, Qué.; Department of Family Medicine (Paterson), McMaster University, Hamilton, Ont.; Departments of Epidemiology and Biostatistics and of Pediatrics (Platt), McGill University, Montréal, Que. 
Contributors: David Henry, Colin Dormuth, Brandace Winquist, Anick Bérard, Linda Lévesque and Robert Platt contributed substantially to conception and design of the study. Colin Dormuth, Brandace Winquist, Greg Carney, Shawn Bugden, Gary Teare, Michael Paterson and Robert Platt contributed substantially to the acquisition and analysis of data. David Henry, Colin Dormuth, Brandace Winquist and Robert Platt drafted the article, and all of the authors revised it critically for accuracy and important intellectual content. All of the authors gave final approval of the version to be published and agreed to act as guarantors of the work.

Funding: The Canadian Network for Observational Drug Effect Studies (CNODES), a collaborating centre of the Drug Safety and Effectiveness Network, is funded by the Canadian Institutes of Health Research (grant DSE-111845). This study was made possible through data-sharing agreements between CNODES member research centres and the respective provincial governments of British Columbia, Saskatchewan, Manitoba (project no. HIPC\#2012/2013-52) and Ontario. The opinions, results and conclusions reported in this paper are those of the authors. No endorsement by the provinces is intended or should be inferred.

Canadian Network for Observational Drug Effect Studies (CNODES) Investigators: Samy Suissa (principal investigator); Colin Dormuth (British Columbia); Brenda R.
Hemmelgarn (Alberta); Gary Teare (Saskatchewan); Patricia Caetano and Dan Chateau (Manitoba); David Henry and J. Michael Paterson (Ontario); Jacques LeLorier (Quebec); Adrian R. Levy (Nova Scotia); Pierre Ernst (UK Clinical Practice Research Datalink); Robert W. Platt (Methods); and Ingrid S. Sketris (Knowledge Translation).

Acknowledgements: The authors acknowledge the contributions of the CNODES collaborators and the assistants at each site: Matthew Dahl, Fangyun Wu, Nianping Hu, Odile Sheehy. British Columbia data sources, as well as details of research ethics approvals, are provided in Appendix 2 (available at www.cmaj.ca/lookup/suppl/doi:10.1503/cmaj. 151243/-/DC1).

Disclaimers: This study was supported by the Institute for Clinical Evaluative Sciences (ICES), which is funded by an annual grant from the Ontario Ministry of Health and LongTerm Care (MOHLTC). The opinions, results and conclusions reported in this paper are those of the authors and are independent from the funding sources. No endorsement by ICES or the Ontario MOHLTC is intended or should be inferred. Parts of this material are based on data and information compiled and provided by the Canadian Institute for Health Information (CIHI). However, the analyses, conclusions, opinions and statements expressed herein are those of the authors, and not necessarily those of CIHI. 